\title{
Adrenal and ovarian sources of progesterone secretion in young female fallow deer, Dama dama
}

\author{
G. W. Asher, A. J. Peterson and D. Duganzich \\ Ruakura Agricultural Centre, Ministry of Agriculture and Fisheries, Private Bag, Hamilton, \\ New Zealand
}

\begin{abstract}
Summary. Six young female fallow deer, including 3 that were ovariectomized at 9 months of age, were blood sampled at frequent intervals after i.v. injections of (1) ACTH analogue (tetracosactrin), (2) GnRH analogue (buserelin) and (3) saline solution on separate occasions at $11,13,15$ and 18 months of age. Relative to prechallenge plasma values, ACTH administration resulted in a 4-10-fold increase in mean plasma progesterone concentrations, but only a $10-45 \%$ increase in mean plasma cortisol concentrations, within $40 \mathrm{~min}$ for entire and ovariectomized does during the prepubertal periods (11,13 and 15 months) and for ovariectomized does during the post-pubertal period (18 months). Post-pubertal entire does exhibited high mean basal plasma progesterone concentrations $(3-4 \mathrm{ng} / \mathrm{ml})$ indicating a luteal source of secretion, with the ACTH-induced progesterone response being additive to the luteal progesterone but of similar magnitude to responses in the ovariectomized does. There was no significant ACTH challenge effect on mean plasma $\mathrm{LH}$ concentrations for entire or ovariectomized does at all ages.

GnRH administration had no significant effects on mean plasma concentrations of progesterone and cortisol of entire and ovariectomized does, although there was a small increase in mean plasma progesterone values in post-pubertal does that may have reflected a luteal response to $\mathrm{GnRH}$ (via $\mathrm{LH}$ ). GnRH challenge resulted in marked increases in mean plasma LH concentrations but the response patterns were different for the 2 types of does, being more rapid and of higher magnitude for ovariectomized does.
\end{abstract}

Saline injections had no significant effects on mean plasma hormone concentrations for entire and ovariectomized does at any age.

It is concluded that the adrenal glands are secondary and major sources of progesterone in fallow deer and that there exists a two-phase response of adrenal glands to stress/ACTH stimulation in terms of cortisol and progesterone secretion.

Keywords: fallow deer, progesterone, cortisol; adrenal gland; corpus luteum

\section{Introduction}

The corpus luteum appears to be the principal source of progesterone in female deer, particularly during the oestrous cycle (e.g. fallow deer, Dama dama: Asher, 1985; Asher \& Smith, 1987; red deer, Cervus elaphus: Adam et al., 1985; Pere David's deer, Elaphurus davidianus: Curlewis et al., 1988; white-tailed deer, Odocoileus virginianus: Harder \& Moorhead, 1980) and early pregnancy (e.g. fallow deer: Asher, 1986, 1987; red deer: Kelly et al., 1982; Adam et al., 1985). However, certain anomalies in plasma progesterone concentrations observed occasionally in female red deer and fallow deer cannot be explained in terms of luteal secretion of the hormone. Kelly et al. (1985) 
recorded erratic fluctuations in plasma progesterone concentrations during the peri-oestrous period of mature red deer hinds. Similarly, a single short-duration $(2-3 \mathrm{~h})$, high-amplitude ( $>5 \mathrm{ng} / \mathrm{ml}$ ) pulse of plasma progesterone was observed at the onset of oestrus of a mature fallow doe (Asher et al., 1986). Unusual incidences of progesterone secretion are not confined to adult female deer. Asher (1986) recorded an increase in mean plasma progesterone concentrations, from 0.5 to $2.0 \mathrm{ng} / \mathrm{ml}$, in immature fallow does between 10 and 15 months of age and erratic fluctuations in plasma progesterone concentrations (up to $7 \mathrm{ng} / \mathrm{ml}$ ) occurred in twice-weekly samples from immature does (Asher et al., 1988b). As significant quantities of active luteal tissue are unlikely to be present before sexual maturity or during the peri-oestrous period, it seems likely that the progesterone observed in these studies was derived from extra-ovarian sources.

Progesterone is known to be secreted in significant amounts by the adrenal glands of rats (Resko, 1969; Fajer et al., 1971), ewes (Green \& Moor, 1977) and cows (Gwazdauskas et al., 1972; Wagner et al., 1972). Furthermore, Wesson et al. (1979) observed a significant rise in plasma progesterone concentrations in female white-tailed deer $30 \mathrm{~min}$ after immobilization with the muscle relaxant, succinyl-choline chloride, and concluded that increased stress while under nonsedated chemical restraint resulted in increased adrenal secretion of progesterone. From a series of experiments involving the use of anaesthetic drugs and ACTH stimulation/dexamethasone depression of adrenal activity, Plotka et al. (1983) provided further evidence of adrenal progesterone secretion in female and male white-tailed deer.

These studies lend support to the hypothesis that the adrenal glands may be a secondary source of progesterone in fallow deer (Asher, 1986). The present study aimed to test this hypothesis for entire and ovariectomized fallow does between 10 and 18 months of age by measuring the hormonal responses to ACTH-analogue challenge of adrenal tissue and GnRH-analogue challenge (and hence LH challenge) of luteal tissue.

\section{Materials and Methods}

Animals and management. Six immature fallow does, born in December 1985, were selected in July 1986 (8 months of age) at a uniform liveweight $(25-27 \mathrm{~kg})$. Three of the does were ovariectomized on 13 August (9 months) using anaesthetic and surgical procedures similar to those described by Asher et al. (1988a) for hysterectomy surgery on adult does.

The deer were contained in high-fenced paddocks with 18 other does of the same age and were grazed on ryegrassclover pastures.

Blood sampling. During the months of October (11 months), January (13 months), March (I5 months) and June (18 months, after sexual maturation) the 6 does were held indoors from 08:00 to 17:00 h $(9 \mathrm{~h})$ on 3 separate occasions and subjected to an intensive blood sampling regimen following physiological challenges with ACTH analogue, GnRH analogue or saline solution (i.e. control).

On 7 October, 14 January, $31 \mathrm{March}$ and 8 June each doe received an i.v. injection of $125 \mu \mathrm{g}$ tetracosactrin $(0 \cdot 5 \mathrm{ml}$ Synacthen: Ciba Geigy Ltd, Basle, Switzerland) at 09:00 h. They were blood sampled at $-60,-40,-20,0,10,20$, $40,60,90,120,150,180,240,300,360$ and $480 \mathrm{~min}$ from the challenge. The entire procedure was repeated from an i.v. challenge of $4 \mu \mathrm{g}$ buserelin ( $1.0 \mathrm{ml}$ Receptal: Hoechst Veterinar GmbH, Munchen, FRG) on 29 October, 7 January, $25 \mathrm{March}$ and $15 \mathrm{June}$, and for an i.v. challenge of $1.0 \mathrm{ml}$ saline solution $(9 \mathrm{~g} \mathrm{NaCl} / \mathrm{l})$ on 16 October, $21 \mathrm{January}, 3$ April and 19 June.

The does were blood sampled $(5 \mathrm{ml})$ by jugular venepuncture ( 21 -gauge needles) into heparinized Vacutainers while individually restrained in a cradle device. Their necks had been shaven previously to facilitate venepuncture from the right external jugular vein. Intravenous injections were administered into the left external jugular vein. Blood samples were centrifuged immediately after collection and the plasma was stored at $-10^{\circ} \mathrm{C}$ until assayed.

Hormone assays. Plasma samples $(n=1152)$ were assayed for progesterone, cortisol and luteinizing hormone (LH) by radioimmunoassay techniques.

Plasma progesterone concentrations were measured by a procedure similar to that described by Fairclough $e t$ al. (1975a) and validated previously for fallow deer serum (Asher, 1985). The antiserum was raised in a rabbit against progesterone-11-BSA conjugate and used at a final dilution of 1:3000. The only significant cross-reaction of a wide range of steroids, including cortisol, tested in the assay was cholesterol $(1 \cdot 5 \%)$. Sensitivity of the standard curve was $0.03 \mathrm{ng}$ per tube $(0.15 \mathrm{ng} / \mathrm{ml}$ plasma) and the intra- and inter-assay coefficients of variation were $6.2 \%$ and $15.8 \%$ respectively. 
Plasma cortisol concentrations were measured by a procedure similar to that described for progesterone (Fairclough et al., 1975b). The antiserum was raised in an ovariectomized ewe against cortisol-3-CMO-BSA and used at a final dilution of 1:3000. Cross-reactivity with other steroids occurred to the following extent: deoxy-17hydroxycorticosterone $5.7 \%$, cortisone $1.2 \%$, corticosterone $0.8 \%$, dexamethasone $0.02 \%$, deoxycorticosterone $0.005 \%$, progesterone and all other steroids tested $<0.005 \%$. The mean recovery ( \pm s.d.) of cortisol added to charcoal-stripped plasma was $94 \cdot 8 \pm 10 \cdot 1 \%$ at $50 \mathrm{ng} / \mathrm{ml}(n=50$ determinations $), 100 \cdot 7 \pm 13.3 \%$ at $100 \mathrm{ng} / \mathrm{ml}$ $(n=48), 100 \cdot 2 \pm 14 \cdot 4 \%$ at $200 \mathrm{ng} / \mathrm{ml}(n=47)$ and $90 \cdot 0 \pm 12 \cdot 8 \%$ at $500 \mathrm{ng} / \mathrm{ml}(n=32)$. Extraction efficiency of radioactive cortisol in plasma was $94.2 \pm 2.7 \%(n=10$ determinations). All samples from an individual challenge were included in a single assay. The inter-assay coefficients of variation were $10 \cdot 6 \%, 13 \cdot 2 \%, 14 \cdot 4 \%$ and $14.4 \%$ for 50 , 100,200 and $500 \mathrm{ng} / \mathrm{ml}$ control samples respectively. The intra-assay coefficient of variation, calculated from multiple determinations of the $100 \mathrm{ng} / \mathrm{ml}$ control sample was $8.8 \%$ and the sensitivity of the standard curve was $0 \cdot 10 \mathrm{ng}$ per tube (10 $\mathrm{ng} / \mathrm{ml}$ plasma).

Luteinizing hormone $(\mathrm{LH})$ concentrations were determined using a heterologous radioimmunoassay procedure described for sheep plasma by Scaramuzzi et al. (1970). The entire assay has been validated previously for fallow deer serum and plasma (Asher $e t$ al., 1986). Sheep pituitary LH preparations used for standards and iodinated tracer were NIH-LH-S11. The LH antibody, which had been raised in a rabbit also using NIH-LH-S1 1 as the antigen, was used in the assay at a final dilution of 1:200 000. Cross-reactivity with other proteins has been described previously (Kelly et al., 1982; Asher et al., 1986). Serial dilutions of pooled serum or plasma from oestrous does with high concentrations of immunoreactive LH gave inhibition curves parallel to those generated for NIH-LH-S11 in buffer (Asher et al., 1986). The inter-assay coefficients of variation, calculated from determinations of sheep (mean concentration $=4.8 \mathrm{ng} / \mathrm{ml}$ ) and deer $($ mean $=3.2 \mathrm{ng} / \mathrm{ml}$ ) control samples in each assay $(n=4$ assays) were $12.7 \%$ and $14.2 \%$ respectively. The intra-assay coefficients of variation for multiple determinations of the same control samples were $5 \cdot 2 \%$ and $7.0 \%$ respectively. The sensitivity of the standard curve was $0.03 \mathrm{ng} \mathrm{NIH-LH-S11}$ per tube $(0 \cdot 30 \mathrm{ng} / \mathrm{ml})$.

Statistical analysis. The data were log-transformed and subjected to analysis of variance in which challenge type (ACTH, GnRH and saline), age (11, 13,15 and 18 months) and their interaction, plus interactions of these with doe type (entire and ovariectomized), were tested against corresponding variation between does. The data are presented graphically as non-transformed means (+l s.e.m.).

\section{Results}

\section{Progesterone responses}

During the 3 prepubertal age periods $(11,13$ and 15 months) there was a significant effect of challenge type (ACTH vs GnRH and saline; $P<0.001$ ), but no apparent effect of doe type $(P>0 \cdot 1)$, on plasma progesterone concentrations (Fig. 1). For entire and ovariectomized does, ACTH injection resulted in a 4-10-fold increase in mean plasma progesterone concentrations to attain peak values $(4-8 \mathrm{ng} / \mathrm{ml})$ within $40 \mathrm{~min}$ after challenge. The concentrations declined progressively from 40 to $180 \mathrm{~min}$ after challenge. GnRH challenge and saline injection did not result in increases in mean plasma progesterone concentrations during the prepubertal period. As with ACTH challenge, mean values towards the end of each sampling session were generally lower than corresponding pre-challenge values.

During the post-pubertal period (18 months) there was a significant difference between entire and ovariectomized does in mean progesterone concentrations before and after challenge with GnRH $(P<0.001)$, being 3-4 ng/ml for entire does and $0.3-1.0 \mathrm{ng} / \mathrm{ml}$ for ovariectomized does (Fig. 1). However, the response to ACTH challenge was of similar magnitude for both types of does ( $\sim 6 \mathrm{ng} / \mathrm{ml}$ above respective basal values) and of similar magnitude to ACTH-induced changes observed in the prepubertal period. The entire does exhibited a small, non-significant $(P>0 \cdot 1)$ rise in mean plasma progesterone concentrations immediately after $\mathrm{GnRH}$ challenge (i.e. $\sim 25 \%$ increase) that was not apparent for the ovariectomized does or for both types of does following saline injection.

\section{Cortisol responses}

Throughout the 4 age periods there was no significant effect of doe type on the pattern of plasma cortisol changes $(P>0 \cdot 1)$ but there was a significant challenge effect $(P<0 \cdot 001)$ (Fig. 2$)$. Mean pre-challenge plasma cortisol concentrations of entire and ovariectomized does varied 


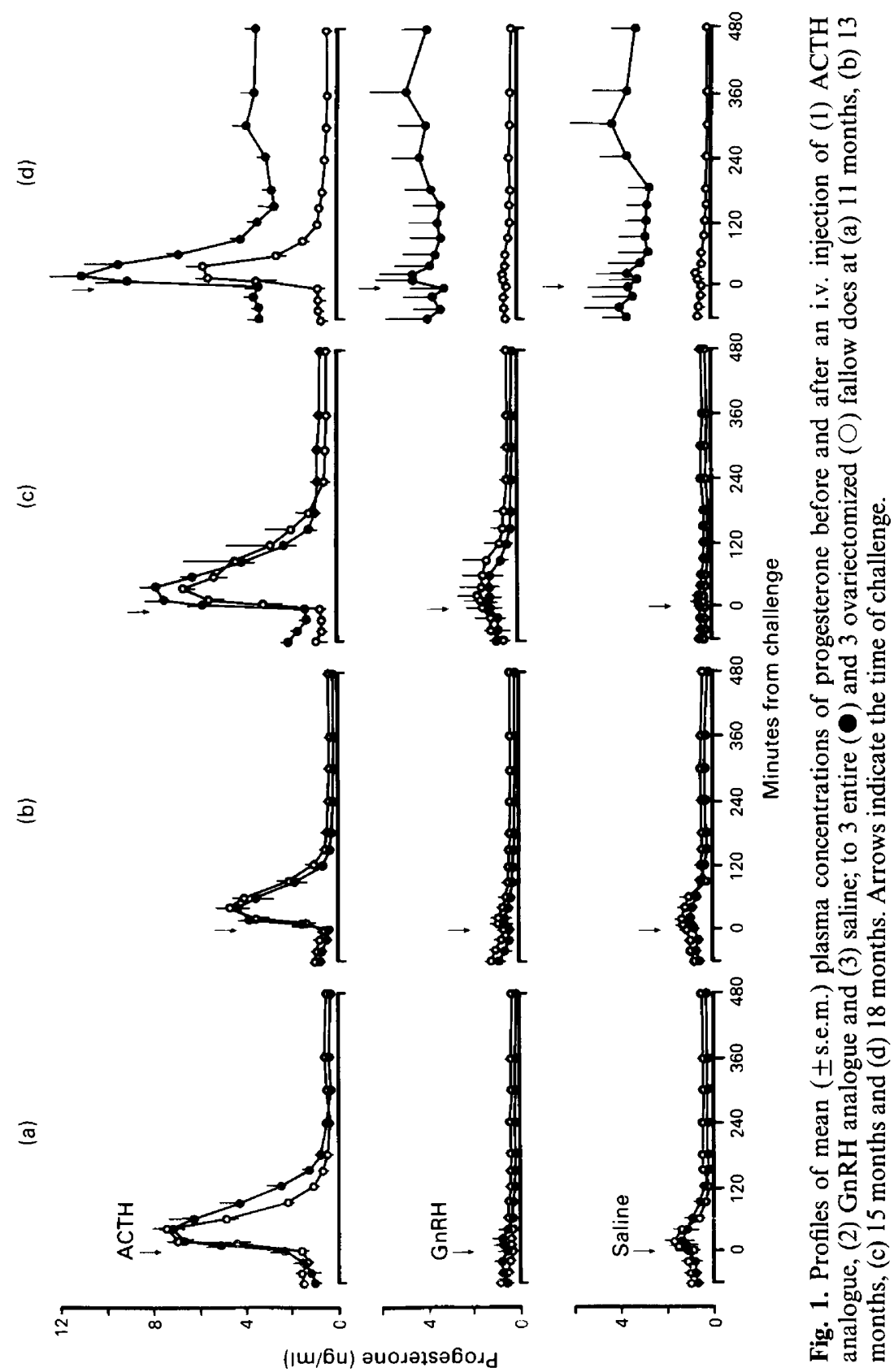


between 60 and $160 \mathrm{ng} / \mathrm{ml}$. ACTH challenge increased basal concentrations by $10-45 \%$ within $20 \mathrm{~min}$ after challenge. Thereafter, concentrations declined progressively to reach mean values $50-70 \%$ lower than pre-challenge values. GnRH challenge and saline injection did not result in any significant increase in mean plasma cortisol concentration $(P>0 \cdot 1)$ but there was a similar reduction in values towards the end of each sampling session as occurred during ACTH challenge sessions (Fig. 2).

\section{LH responses}

There were significant challenge type and doe type effects on mean plasma $\mathrm{LH}$ concentrations $(P<0.001)$ (Fig. 3). Throughout the 4 age periods mean plasma LH concentrations before challenge were consistently higher for ovariectomized does $(3-4 \mathrm{ng} / \mathrm{ml})$ than for entire does $(0.5-1.0 \mathrm{ng} / \mathrm{ml})$. The principal challenge effect was observed following GnRH injection, although the response pattern was markedly different between entire and ovariectomized does. Mean plasma LH concentrations for entire does increased progressively after $\mathrm{GnRH}$ administration to attain maximal values $8-24$-fold higher (i.e. $12-18 \mathrm{ng} / \mathrm{ml}$ ) than pre-challenge values within about $150 \mathrm{~min}$. In contrast, maximal values for ovariectomized does (i.e. $20-28 \mathrm{ng} / \mathrm{ml}$ ) were reached within $40 \mathrm{~min}$. Both types of does subsequently exhibited a progressive decline in mean plasma $\mathrm{LH}$ values to reach pre-challenge concentrations by $480 \mathrm{~min}$ (Fig. 3).

Neither ACTH challenge nor saline injection had any significant effects on mean plasma $\mathbf{L H}$ concentrations $(P>0 \cdot 1)$.

\section{Discussion}

The rapid elevation of plasma progesterone concentrations in ovariectomized and entire fallow does after ACTH administration clearly implicates the adrenal glands as a major source of the hormone in this species. It seems likely, therefore, that the occasional anomalous progesterone profiles observed in fallow deer, and other cervid species, also represent adrenal progesterone secretion in response to various stressors.

Plasma progesterone concentrations following ACTH challenge were similar to peripheral plasma concentrations of apparent luteal origin occurring during the oestrous cycle (Asher, 1985) and pregnancy (Asher, 1987). Likewise, erratic fluctuations in plasma progesterone concentrations during the perioestrous period of some red deer hinds (Kelly et al., 1985) were similar to concentrations presumably derived from luteal sources (Adam et al., 1985). Furthermore, adrenal glands of white-tailed deer does contribute more than $3 \mathrm{ng}$ progesterone/ml to the peripheral circulatory system (Plotka et al., 1983). Thus progesterone of adrenal origin may occasionally confound interpretation of plasma progesterone profiles for a number of deer species. For example, high mean basal concentrations of plasma progesterone $(3-4 \mathrm{ng} / \mathrm{ml})$ in the entire fallow does at 18 months of age (Fig. 1d) undoubtedly reflect active corpora lutea after sexual maturation. Progesterone of adrenal origin, as a consequence of $\mathrm{ACTH}$ administration, was clearly additive to that of ovarian origin, and in the absence of pre-challenge data (or indeed the effect of stress stimuli) it would be impossible to differentiate the relative contributions of the two sources of secretion.

While plasma progesterone data clearly indicate the presence of active luteal tissue in 18-monthold entire does there is little indication of a major effect of GnRH challenge (and hence, LH stimulation) on luteal progesterone secretion. This type of challenge may not be a useful indicator of the presence of active luteal tissue in mature fallow deer, as had been postulated at the start of the trial. The complete failure of exogenous $\mathrm{GnRH}$ to stimulate progesterone secretion in sexually immature does (i.e. 11-15 months) most probably reflects the absence of luteal tissue for such tissue is only found after sexual maturation at 16 months of age (Armstrong et al., 1969; Chapman \& Chapman, 1969, 1975; Baker, 1973). However, plasma LH concentrations of ovariectomized fallow 


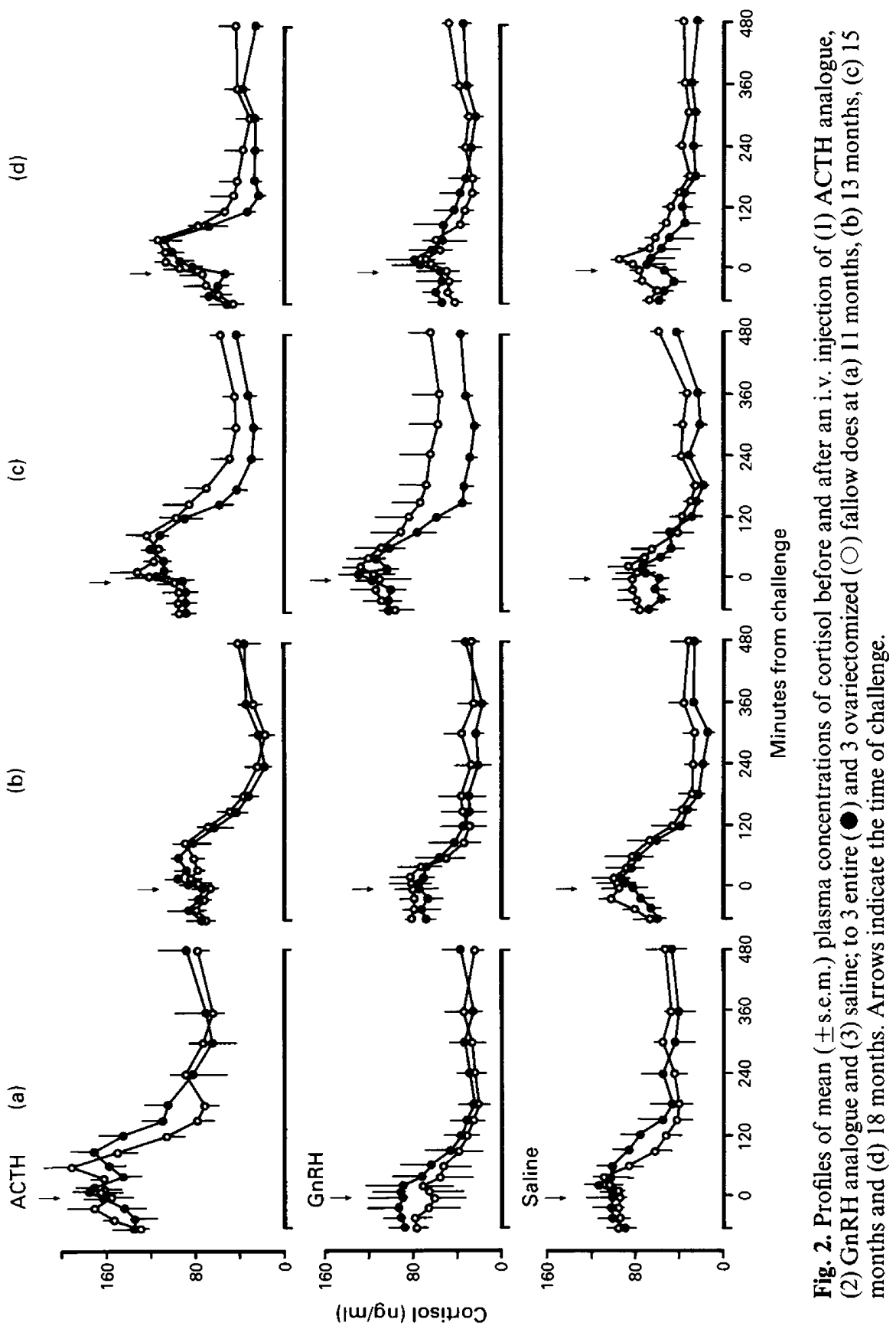



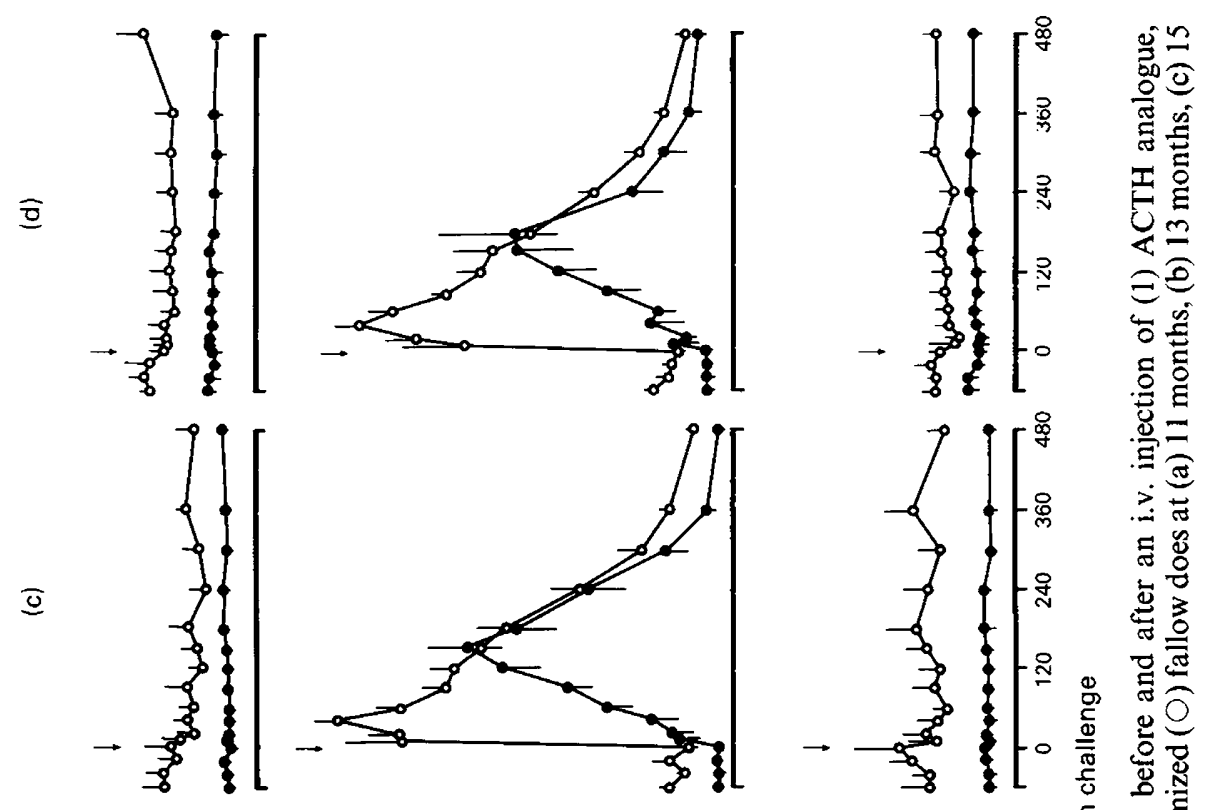

ב

可

席

है

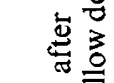

壱

Ф)

总
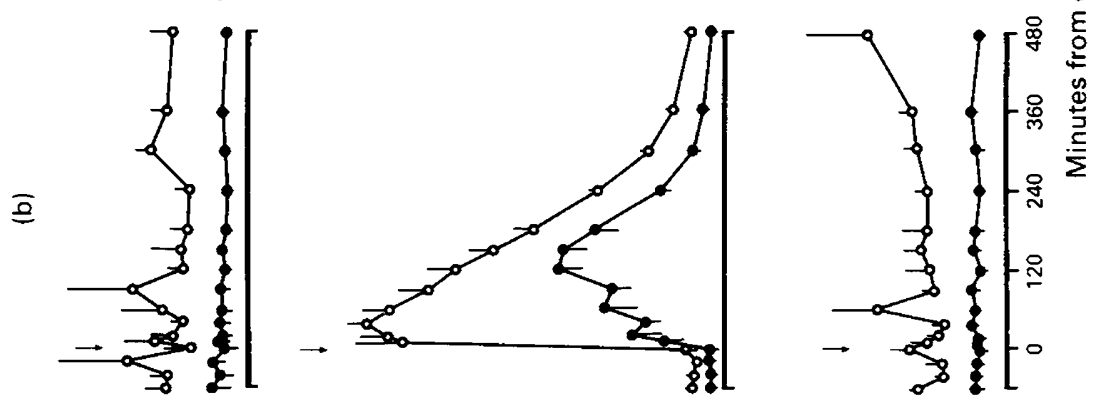

工

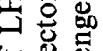

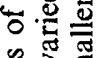

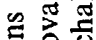

응

范范

政

8

疍

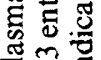

용.
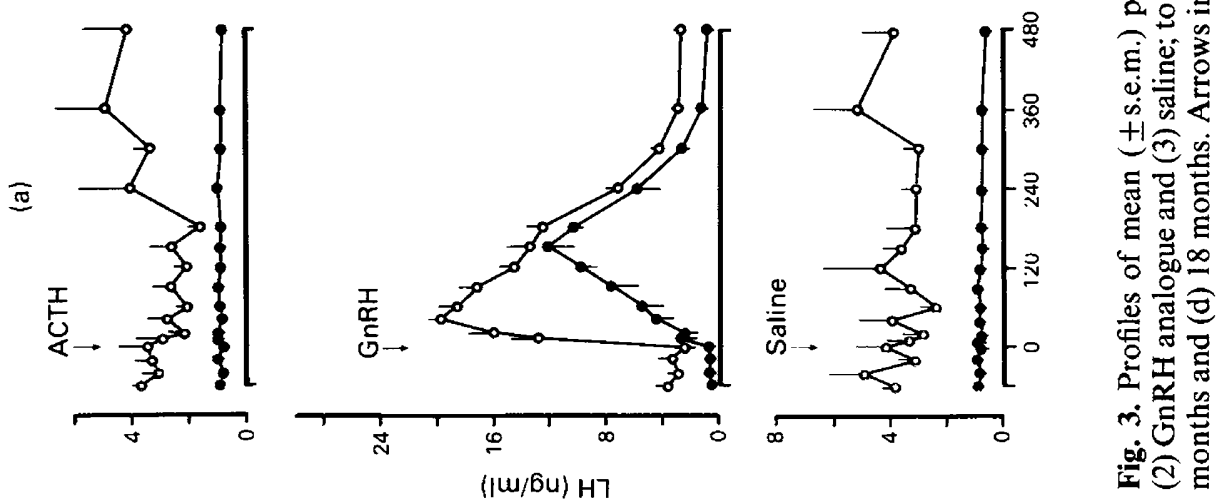
does were notably higher than for entire does, indicating that the negative gonadal feedback on pituitary function was effective even in immature animals. Differential responses by ovariectomized and entire does to GnRH challenge indicate possible gonadal modulation of pituitary response to GnRH that was manifest by extremely rapid, high-amplitude $\mathrm{LH}$ secretion following GnRH administration in ovariectomized does compared with a more gradual, lower-amplitude response in entire does.

Plasma cortisol concentrations observed in this study were very high at the start of each blood sampling session and declined progressively to attain considerably lower final concentrations. Cortisol concentrations did not increase markedly in response to ACTH challenge, whereas those of progesterone did. Perhaps the high levels of stress at the start of each experiment caused maximal adrenal secretion of cortisol, such that additional stimulation with exogenous ACTH was without a marked response. The present results suggest that large quantities of cortisol and modest quantities of progesterone are secreted by the adrenal cortex of fallow deer in response to most stress stimuli. However, under extreme stress, progesterone, rather than additional quantities of cortisol, is secreted in large amounts.

There has been considerable speculation on how the adrenal gland might influence reproductive function in mammals (reviews: Parkes \& Deanesly, 1966; Moberg, 1985). Adrenal progesterone secretion may affect various components of the reproductive process. For example, Plotka et al. (1983) postulated that adrenal progesterone in white-tailed deer may help to maintain pregnancy during periods of stress by neutralizing the pregnancy-terminating action of cortisol. Alternatively, high blood progesterone concentrations after adrenal stimulation may inhibit oestrus and ovulation during the breeding season, thus preventing pregnancy under highly stressful conditions. Our blood sampling regimen lacked sufficient precision and duration to detect any possible changes in $\mathrm{LH}$ pulse frequency in response to adrenal progesterone secretion in fallow does.

Evidence that progesterone secretion, possibly of adrenal origin, may affect LH secretion during the breeding season of fallow deer was provided by Asher et al. (1986) who reported a mature doe with a very high plasma concentration $(>5 \mathrm{ng} / \mathrm{ml})$ of progesterone, at the onset of oestrus, which appeared to depress the preovulatory LH surge. However, this situation, and that from the present study, only related to transitory stimulation of the adrenal glands, resulting in transient increases in progesterone secretion. Sustained adrenal stimulation associated with environmental or social stressors could have more long-term effects on reproduction in fallow deer.

We thank M. Langridge, O. C. Chitty and H. H. Humble for assistance with animal handling and blood sampling; R. Shanley, S. Parratt and L. ter Veer for hormone analyses; Dr A. J. Pearson for useful comments on earlier draft manuscripts; and Ciba Geigy Ltd for the kind donation of Synacthen.

\section{References}

Adam, C.L., Moir, C.E. \& Atkinson, T. (1985) Plasma concentrations of progesterone in female red deer (Cervus elaphus) during the breeding season, pregnancy and anoestrus. J. Reprod. Fert. 74, 631-636.

Armstrong, N., Chaplin, R.E., Chapman, D.I. \& Smith, B. (1969) Observations on the reproduction of female wild and park fallow deer (Dama dama) in southern England. J. Zool., Lond. 158, 27-37.

Asher, G.W. (1985) Oestrous cycle and breeding season of farmed fallow deer, Dama dama. J. Reprod. Fert. 75, 521-529.

Asher, G.W. (1986) Studies on the reproduction of farmed fallow deer (Dama dama). Ph.D. thesis, University of Canterbury, New Zealand.

Asher, G.W. (1987) Conception rates, gestation length, liveweight changes and serum progesterone concentrations during the breeding season and pregnancy of farmed female fallow deer. Proc. 4th AAAP Animal Sciences Congress, Hamilton, New Zealand, p. 247, Abstr.

Asher, G.W. \& Smith, J.F. (1987) Induction of oestrus and ovulation in farmed fallow deer (Dama dama) by using progesterone and PMSG treatment. J. Reprod. Fert. 81, 113-118.

Asher, G.W., Barrell, G.K. \& Peterson, A.J. (1986) Hormonal changes around oestrus of farmed fallow deer, Dama dama. J. Reprod. Fert. 78, 487-496.

Asher, G.W., Peterson, A.J. \& Watkins, W.B. (1988a) Hormonal changes during luteal regression in farmed fallow deer, Dama dama. J. Reprod. Fert. 84, 379-386. 
Asher, G.W., Barrell, G.K., Adam, J.L. \& Staples, L. (1988b) Effects of subcutaneous melatonin implants on reproductive seasonality of farmed fallow deer (Dama dama). J. Reprod. Fert. 84, 679-691.

Baker, K. (1973) Reproduction biology of fallow deer (Dama dama) in the Blue Mountains of New Zealand. M.Sc. thesis, University of Otago, Dunedin, New Zealand.

Chapman, D.I. \& Chapman, N. (1969) Observations on the biology of fallow deer (Dama dama) in Epping Forest, Essex, England. Biological Conservation 2, 5562 .

Chapman, D.I. \& Chapman, N. (1975) Fallow Deer: their History, Distribution and Biology. Terence Datton Ltd, Lavenham, U.K.

Curlewis, J.D., Loudon, A.S.I. \& Coleman, A.P.M. (1988) Oestrous cycles and the breeding season of the Pere David's deer hind (Elephurus davidianus). $J$. Reprod. Fert. 82, 119-126.

Fairclough, R.J., Hunter, J.T. \& Welch, R.A.S. (1975a) Peripheral plasma progesterone and utero-ovarian prostaglandin $F$ concentrations in the cow around parturition. Prostaglandins 9, 901-914.

Fairclough, R.J., Hunter, J.T., Welch, R.A.S. \& Payne, E. (1975b) Plasma corticosteroid concentrations in the bovine foetus near term. J. Endocr. 65, $139-140$.

Fajer, A.B., Holzbauer, M. \& Newport, H.M. (1971) The contribution of the adrenal gland to the total amount of progesterone produced in the female rat. $J$. Physiol., Lond. 214, 115-126.

Green, D. \& Moor, R.M. (1977) The influence of anaesthesia on the concentration of progesterone and cortisol in peripheral blood plasma of sheep. Res. vet. Sci. 22, 122-123.

Gwazdauskas, F.C., Thatcher, W.W. \& Wilcox, C.J. (1972) Adrenocorticotropin alteration of bovine peripheral plasma concentrations of cortisol, corticosterone and progesterone. J. Dairy Sci. 55, $1165-1169$.

Harder, J.D. \& Moorhead, D.L. (1980) Development of corpora lutea and plasma progesterone levels associ- ated with the onset of the breeding season in whitetailed deer (Odocoileus virginianus). Biol. Reprod. 22, 185-191.

Kelly, R.W., McNatty, K.P., Moore, G.H., Ross, D. \& Gibb, M. (1982) Plasma concentrations of LH, prolactin, oestradiol and progesterone in female red deer (Cervus elaphus) during pregnancy. J. Reprod. Fert. 64, 475-483.

Kelly, R.W., McNatty, K.P. \& Moore, G.H. (1985) Hormonal changes about oestrus in female red deer. In Biology of Deer Production, pp. 181-184. Eds P. F. Fennessy \& K. R. Drew. The Royal Society of New Zealand, Wellington, N.Z.

Moberg, G.P. (1985) Influence of stress on reproduction: measure of well-being. In Animal Stress, pp. 245-267. Ed. G. P. Moberg. American Physiology Society, Bethesda.

Parkes, A.S. \& Deanesly, R. (1966) Relation between the gonads and the adrenal glands. In Marshall's Physiology of Reproduction, 3rd edn, vol. 3, pp. 1064-1100. Ed. A. S. Parkes. Longmans, Green \& Co. Ltd, London.

Plotka, E.D., Seal, U.S., Verme, L.J. \& Ozoga, J.J. (1983) The adrenal gland in white-tailed deer: a significant source of progesterone. J. Wildl. Mgmt 47, $38-44$.

Resko, J.A. (1969) Endocrine control of adrenal progesterone secretion in the ovariectomised rat. Science, N.Y. 164, 70.

Scaramuzzi, R.J., Caldwell, B.V. \& Moor, R.M. (1970) Radioimmunoassay of $\mathrm{LH}$ and estrogen during the estrous cycle of the ewe. Biol. Reprod. 3, 110-119.

Wagner, W.C., Strohbelm, R.E. \& Harris, P.A. (1972) ACTH, corticoids and luteal function in heifers. $J$. Anim. Sci. 35, 789-793.

Wesson, J.A., Scanlon, P.F., Kirkpatrick, R.L., Mosby, H.S. \& Butcher, R.L. (1979) Influence of chemical immobilisation and physical restraint on steroid hormone levels in blood of white-tailed deer. Can. J. Zool. 57, 768-776.

Received 2 August 1988 